\title{
Dermoscopic features of thin melanomas: a comparative study of melanoma in situ and invasive melanomas smaller than or equal to $1 \mathrm{~mm}^{*}$
}

\author{
Características dermatoscópicas de melanomas finos: estudo comparativo entre \\ melanomas in situ e melanomas invasivos menores ou iguais a $1 \mathrm{~mm}$ \\ Vanessa Priscilla Martins da Silva ${ }^{1}$ \\ Daniel Holthausen Nunes ${ }^{4}$ \\ Juliana Kida Ikino ${ }^{2}$ \\ Gabriella Di Giunta ${ }^{5}$ \\ Mariana Mazzochi Sens ${ }^{3}$
}

DOI: http://dx.doi.org/10.1590/abd1806-4841.20132017

\begin{abstract}
BACKGROUND: Dermoscopy allows the early detection of melanomas. The preoperative determination of Breslow index by dermoscopy could be useful in planning the surgical approach and in selecting patients for sentinel lymph node biopsy. OвJеctives: This study aims at describing the dermoscopic features of thin melanomas and comparing melanomas in situ with invasive melanomas less than or equal to $1 \mathrm{~mm}$ thick. METHODS: This was an observational retrospective study in which the dermoscopy photographs of 41 thin melanomas were evaluated. Three observers evaluated together 14 dermoscopic criteria. RESULTS: Among thin melanomas, the most frequent criteria were presence of asymmetry in two axes in 95\% of cases (39 cases), 3 or more colors in $80.4 \%$ of cases (33 cases), atypical dots or globules in $58.5 \%$ of cases (24 cases) and atypical network or streaks in $53.6 \%$ of cases (22 cases). The group of invasive melanomas presented with a higher frequency and statistical significance ( $\mathrm{p}<0.05) 3$ or more colors (OR: 16.1), milky red areas (OR: 4.8) and blue-white veil (OR: 20.4), and a greater tendency to have streaks or atypical network (OR: 3.66). ConcLusIONS: Thin melanomas tend to have asymmetry in the two axes, 3 or more colors, atypical dots or globules and atypical network or streaks. Melanomas in situ tend to have up to 2 colors, no blue-white veil and no milky red area. Invasive melanomas tend to have 3 or more colors, a milky red area, blue-white veil, and atypical network or streaks. Further studies are needed to confirm these findings.
\end{abstract}

Keywords: Dermoscopy; Melanoma; Skin neoplasms

Resumo: Fundamentos: A dermatoscopia propicia o diagnóstico mais precoce do melanoma. A estimativa préoperatória da espessura de Breslow através da dermatoscopia poderia ser útil no planejamento da conduta cirúrgica e seleção dos pacientes para a biópsia de linfonodo sentinela. OBjETIVOs: Este estudo objetiva descrever as características dermatoscópicas encontradas em melanomas finos e comparar melanomas in situ com melanomas invasivos menores ou iguais a $1 \mathrm{~mm}$. MÉTODOs: Trata-se de estudo observacional, retrospectivo, no qual avaliouse o registro fotográfico da dermatoscopia de 41 melanomas finos. Três observadores avaliaram em conjunto 14 critérios dermatoscópicos. RESULTADOS: Dentre os melanomas finos, os critérios mais encontrados foram: presença de assimetria nos dois eixos em 95\% (39 casos), 3 ou mais cores em 80,4\% (33 casos), pontos ou glóbulos atípicos em 58,5\% (24 casos) e rede atípica ou estrias radiadas em 53,6\% (22 casos). O grupo dos melanomas invasivos apresentou com maior frequência e significância estatística $(\mathrm{p}<0,05)$ a presença de 3 ou mais cores $(\mathrm{OR}: 16,1)$, áreas vermelho-leitosas (OR: 4,8) e véu (OR: 20,4), além de uma maior tendência em apresentar rede atípica ou estrias radiadas (OR: 3,66). CONCLUSÕEs: Os melanomas finos tendem a apresentar assimetria nos dois eixos, 3 ou mais cores, pontos ou glóbulos atípicos e rede atípica ou estrias radiadas. Os melanomas in situ tendem a apresentar até 2 cores, ausência de véu e de área vermelho-leitosa. Os melanomas invasivos tendem a exibir 3 cores ou mais, área vermelho-leitosa, véu, rede atípica ou estrias radiadas. Outros estudos são necessários para a confirmação dos achados.

Palavras-chave: Dermoscopia; Melanoma; Neoplasias cutâneas

Received on 26.07.2012.

Approved by the Advisory Board and accepted for publication on 28.10.2012.

* Work conducted at the University Hospital of the Federal University of Santa Catarina (HU-UFSC) - Florianópolis (SC), Brazil.

Financial Support: None

Conflict of Interest: None.

Dermatologist - Collaborator Preceptor of Dermoscopy and Melanoma at Hospital Universitário Professor Polydoro Ernani de São Thiago, Federal University of Santa Catarina (HU-UFSC) - Florianópolis (SC), Brazil.

Dermatologist - Preceptor of Dermoscopy and Melanoma at Hospital Universitário Professor Polydoro Ernani de São Thiago, Federal University of Santa Catarina (HU-UFSC) - Florianópolis (SC), Brazil.

Dermatologist - Collaborator Preceptor of Phototherapy and Vitiligo at Hospital Universitário Professor Polydoro Ernani de São Thiago, Federal University of Santa Catarina (HU-UFSC) - Florianópolis (SC), Brazil.

M.Sc. in Medical Sciencies - Head of the Dermatology Service of Hospital Universitário Professor Polydoro Ernani de São Thiago, Federal University of Santa Catarina (HU-UFSC) - Florianópolis (SC), Brazil.

PhD in Pathology - Associate Professor, Pathology Service, Federal University of Santa Catarina (UFSC) - Florianópolis (SC), Brazil.

(C)2013 by Anais Brasileiros de Dermatologia 


\section{INTRODUCTION}

Melanoma is an aggressive skin cancer. Even though it is highly mortal, it can be curable and its prognosis can be considered good if the disease is detected at an early stage. ${ }^{1}$ It affects mainly Caucasians, although this type of cancer affects all ethnic groups at different rates. ${ }^{1}$ It is estimated that in 2012 the incidence of melanoma in Brazil was 3,170 new cases in men and 3,060 in women. ${ }^{1}$ The highest estimated rates are found in the South region of the country. ${ }^{1}$ Therefore, studies of the population of this region are of great value.

Considering that current therapies against advanced melanoma are not very effective, early diagnosis and intervention are valuable to reduce mortality. Dermoscopy is a noninvasive technique that allows the visualization of structures in vivo, from the epidermis to the papillary dermis, that are not seen with the naked eye. Dermoscopy is more accurate than clinical examination; it increases sensitivity in up to $10-27 \%$, making the earlier detection of melanoma possible. ${ }^{2,3}$ Besides increasing diagnostic accuracy, it reduces the rate of excision of benign lesions that may be similar to melanoma when seen with the naked eye. ${ }^{4}$

In 1970, Breslow described a simple method to measure the depth of melanoma invasion by means of pathological examination. ${ }^{5}$ The Breslow index is still the simplest and most useful single variable related to prognosis. ${ }^{6}$ The current staging system for melanoma of the American Joint Committee on Cancer uses the Breslow index as the primary attribute of classification. It applies a cut-off of $1.0 \mathrm{~mm}$ instead of the initial cut-off of $0.76 \mathrm{~mm}$ used by Breslow. ${ }^{5,7}$ Melanomas up to $1 \mathrm{~mm}$ thick are defined as thin melanomas because they have a good prognosis, with an 85 to $90 \%^{7}$ chance of a 10-year-survival after surgical excision with a margin of $1 \mathrm{~cm} .{ }^{8}$

Thin melanomas include melanomas in situ and invasive melanomas with a depth less than or equal to $1 \mathrm{~mm}$. Melanoma in situ is a diagnostic entity surgically treated with $0.5 \mathrm{~cm}$ margins, and there have been no deaths resulting from melanomas in situ that were properly excised. ${ }^{8}$ These same surgical margins are recommended in Brazil by the Brazilian Melanoma Group. ${ }^{9}$ Moreover, the Breslow index is one of the criteria used in selecting patients for sentinel lymph node biopsy (SLNB) ${ }^{9,10}$ Whenever possible, SLNB is recommended before wide excision of the primary tumor to minimize destruction of the lymphatic vessels. ${ }^{11}$ Recognition of thin melanomas is also important considering that elective lymph node dissections and extensive staging evaluations are not recommended for patients with thin melanoma.

Preoperative assessment of the Breslow index by dermoscopy and knowledge of the dermoscopic features of thin melanomas may be important in planning the surgical approach and in selecting patients for SLNB at the time of tumor excision. This study aims at describing the dermoscopic features of thin melanomas and evaluating whether there are differences between melanomas in situ and invasive melanomas less than or equal to $1 \mathrm{~mm}$ thick. No similar Brazilian studies have been found in the literature.

\section{MATERIALS AND METHODS}

This was an observational retrospective study. The study included a convenience sample, and the digital photographic record of the dermoscopic images of 41 thin melanomas (less than or equal to 1 $\mathrm{mm}$ thick) was evaluated, totaling 35 patients, dated from 2006 to March 2012. All the patients seen at the Outpatient Clinic of Dermoscopy and Melanoma (Hospital University, Federal University of Santa Catarina) with at least one diagnosis of thin melanoma were considered for data collection. The data were collected from 2011 to March 2012. Patients who did not have a photographic record prior to excisional biopsy, whose record was not adequate or who had undergone an incisional biopsy before the photographic record were excluded from the study. Due to the dermoscopic characteristics of the so-called specials areas (scalp, face, palms, soles and mucous membranes), only lesions in the neck, trunk and limbs were included.

All dermoscopic images were obtained using the Heine Delta 20 $0^{\circledast}$ Dermatoscope (Heine ${ }^{\circledR}$, Germany), with alcohol-gel as linkage fluid. A Nikon UR-E15 ${ }^{\circledast}$ adapter (Nikon ${ }^{\circledR}$, Japan) was used to connect to a Nikon ${ }^{\circledast}$ E8400 camera (Nikon ${ }^{\circledast}$, Japan). In cases of large lesions that could not be included in only one photographic field, multiple images of different areas were obtained to record all tumor areas. Three different observers, blinded to the Breslow index, analyzed the images.

Data such as sex, age, Breslow index and histological type were collected. Through observation of the lesion on the computer, the observers agreed with regard to the presence or absence of the following criteria: asymmetry in 1 or 2 axes, atypical network, streaks, atypical dots, atypical globules, pseudopods, blotches, blue-white veil, structureless area, atypical vessels, milky red area, island, peppering and white scar-like area. For more objectivity, atypical network and streaks were grouped into the same criterion, as well as atypical dots and atypical globules. When there was an island, its type was also noted. The dermatoscopic features associated with the diagnosis of melanoma in this work have been described in previous studies (Table 1). ${ }^{12-16}$ The SPSS (Statistical Package 
TABLE 1: Definitions of the dermoscopic criteria used in the study

\begin{tabular}{|c|c|}
\hline Criterion & Definition \\
\hline Asymmetry in two axes & In 0,1 or 2 perpendicular axes; assess not only contour, but also colors and structures. ${ }^{12}$ \\
\hline Atypical dots/ globules & Black, brown, round to oval, various sizes, irregularly distributed within the lesion. ${ }^{12}$ \\
\hline Atypical network & Black, brown or gray network with irregular holes and thick lines. ${ }^{12}$ \\
\hline Streaks & $\begin{array}{l}\text { Linear structures of brown to black color, of variable thickness, not clearly combined with the lines of the } \\
\text { network. It is most evident in the periphery. }{ }^{15}\end{array}$ \\
\hline Pseudopods & $\begin{array}{l}\text { Bulbous and often kinked projections that are found at the edge of a lesion, either directly connected to the } \\
\text { tumor body or pigmented network. They can never be seen distributed regularly or symmetrically around } \\
\text { the lesion. When connected directly to the tumor body, they must have an acute angle to the tumor edge or } \\
\text { arise from linear or curvilinear extensions. When connected to the network, the width of the bulbous ending } \\
\text { must be greater than the width of any part of the surrounding network and at least double that of its direc- } \\
\text { tly connected network projection. }\end{array}$ \\
\hline Blotches & $\begin{array}{l}\text { Black, brown, and/or gray structureless areas with symmetrical or asymmetrical distribution within the } \\
\text { lesion. }{ }^{12}\end{array}$ \\
\hline Blue-white veil & $\begin{array}{l}\text { Irregular, structureless area of confluent blue pigmentation with an overlying white "ground-glass" film. } \\
\text { The pigmentation cannot cover the entire lesion and usually corresponds to a clinically elevated part of the } \\
\text { lesion. }{ }^{12}\end{array}$ \\
\hline Structureless area & Area with absence of structures larger than $10 \%$ of the total lesion. ${ }^{16}$ \\
\hline Atypical vessels & Linear-irregular or dotted vessels not clearly seen within regression structures. ${ }^{12}$ \\
\hline Milky red area & $\begin{array}{l}\text { Globules and/or larger areas of fuzzy or unfocused milky-red color usually corresponding to an elevated } \\
\text { part of the lesion. }{ }^{14}\end{array}$ \\
\hline Island & $\begin{array}{l}\text { Well-circumscribed area which shows a uniform dermoscopic pattern, different from the rest of the pigmen- } \\
\text { ted lesion. }{ }^{13}\end{array}$ \\
\hline Peppering & Foci of multiple blue or gray dots (not globules) often described as "pepper-like" granules in pattern. ${ }^{12}$ \\
\hline White like-scar area & $\begin{array}{l}\text { Areas of white distinct irregular extensions (true scarring), which should not be confused with hypo- or } \\
\text { depigmentation due to simple loss of melanin. } .^{12}\end{array}$ \\
\hline
\end{tabular}

for Social Sciences) version 17.0 was used in the statistical analysis, with a confidence interval of $95 \%$ and statistical significance of $p<0.05$. To assess the differences between groups, the chi-square test was applied. For variables with fewer than 5 events, Fisher's exact test was used to calculate p. Considering variables for which no event was observed, the value for the calculation of $p$ and OR (odds ratio) was 0.5 .

\section{Ethical aspects}

This study was approved by the Human Research Ethics Committee of the Federal University of Santa Catarina under certificate number 893 and was conducted according to the principles of the Declaration of Helsinki.

\section{RESULTS}

Forty-one (41) thin melanomas were evaluated. They were identified in 35 patients (14 men and 21 women), with a mean age of 57.1 years (24-86 years). Seventeen cases were of melanoma in situ (41.5\%). The average thickness of melanomas, when invasive, was $0.47 \mathrm{~mm}$ (standard deviation of 0.2 ). Of the total, $75 \%$ of invasive melanomas had a Breslow index of up to $0.53 \mathrm{~mm}$. Thirty-seven lesions were classified as superficial spreading. The other melanomas (5 cases), all in situ, were of the lentigo maligna type. 
With regard to the analyzed dermoscopic structures, the following criteria were more frequently observed in all thin melanomas (in situ and invasive): presence of asymmetry in two axes in $95 \%$ of cases (39 cases), 3 or more colors in $80.4 \%$ of cases (33 cases), atypical dots or globules in $58.5 \%$ of cases (24 cases) and atypical network or streaks in $53.6 \%$ of cases (22 cases). The least frequent structures were blotches in $2.4 \%$ of cases (1 case), pseudopods in $4.9 \%$ of cases (2 cases) and island in $7.3 \%$ of cases ( 3 cases). All cases of island were of the reticular type. Table 2 details the frequency of each criterion by group: melanomas in situ, invasive melanomas less than or equal to $1 \mathrm{~mm}$ thick, and the set of all melanomas. Considerable differences were found between the first two groups. The group of invasive melanomas presented with greater frequency and statistical significance $(p<0.05) 3$ or more colors (OR: 16.1), milky red areas (OR: 4.8) and blue-white veil (OR: 20.4). Atypical network or streaks tend to be more frequent in the group of invasive melanomas (OR: 3.66). Regarding the other characteristics analyzed, there were no differences between the groups.

Figure 1 shows the dermoscopic characteristics found in melanomas in situ, while figures 2 and 3 show the characteristics observed in invasive melanomas less than $1 \mathrm{~mm}$ thick.

\section{DISCUSSION}

The Breslow index is a simple and objective measure. Since it is the most useful criterion related to prognosis, it determines surgical margins and the selection of patients for SLNB. Preoperative assessment of the Breslow index using noninvasive methods has been the subject of previous studies. ${ }^{17-23}$ According to the literature, melanomas $<0.76 \mathrm{~mm}$ show a pigmented network more frequently than thicker melanomas, and melanomas $>0.76 \mathrm{~mm}$ more frequently exhibit atypical vessels and blue-gray areas. ${ }^{18,19,21}$

All the thin melanomas in our study showed asymmetry in two axes, 3 or more colors, atypical dots or atypical globules and atypical network or streaks. Asymmetry in two axes is described as a criterion found in $96 \%$ of malignant melanomas, which is consistent with our findings, even though our assessment included only thin melanomas. ${ }^{24}$

Streaks were also found in these melanomas by Gkalpakiotis, who, upon assessing 71 thin melanomas, found streaks in 68 cases. ${ }^{25}$ Some authors have shown that the presence of atypical irregular network is more related to early melanomas $(<1 \mathrm{~mm}){ }^{19,23}$ In 2001, Stante studied 84 cases of melanomas of all thickness. The author found a correlation between

TABLE 2: Frequency of the analyzed criteria in all melanomas and in melanomas in situ and invasive melanomas less than or equal to $1 \mathrm{~mm}$ thick

\begin{tabular}{|c|c|c|c|c|c|c|c|c|}
\hline \multirow[t]{2}{*}{ Criterion } & \multicolumn{2}{|c|}{$\begin{array}{l}\text { Melanomas in situ } \\
\text { (total 17) }\end{array}$} & \multicolumn{2}{|c|}{$\begin{array}{l}\text { Invasive melanomas } \\
\text { (total 24) }\end{array}$} & \multicolumn{2}{|c|}{$\begin{array}{l}\text { Thin melanomas } \\
\text { (total 41) }\end{array}$} & \multirow[t]{2}{*}{ OR (CI 95\%) } & \multirow[t]{2}{*}{$p$ value } \\
\hline & $\mathbf{N}$ & $\%$ & $\mathbf{N}$ & $\%$ & $\mathbf{N}$ & $\%$ & & \\
\hline Atypical network or streaks & 6 & $35.3 \%$ & 16 & $66.7 \%$ & 22 & $53.6 \%$ & $3.66(0.99-13.56)$ & $\mathrm{p}=0.047$ \\
\hline Blue-white veil & 0 & $0 \%$ & 9 & $37.5 \%$ & 9 & $22 \%$ & $20.4(1.08-382.4)$ & $\mathrm{p}=0.017^{*}$ \\
\hline Milky red area & 5 & $29.4 \%$ & 16 & $66.7 \%$ & 21 & $51.2 \%$ & $4.8(1.25-18.42)$ & $\mathrm{p}=0.028^{*}$ \\
\hline Colors ( 3 or more) & 10 & $58.8 \%$ & 23 & $95.8 \%$ & 33 & $80.4 \%$ & $16.1(1.74-148.7)$ & $\mathrm{p}<0.01^{*}$ \\
\hline Asymmetry in two axes & 16 & $94.1 \%$ & 23 & $95.8 \%$ & 39 & $95.1 \%$ & & \\
\hline Atypical dots or atypical globules & 10 & $58.8 \%$ & 14 & $58.3 \%$ & 24 & $58.5 \%$ & & \\
\hline Pseudopods & 0 & $0 \%$ & 2 & $8.3 \%$ & 2 & $4.9 \%$ & & \\
\hline Blotches & 0 & $0 \%$ & 1 & $4.2 \%$ & 1 & $2.4 \%$ & & \\
\hline Structureless area & 11 & $64.7 \%$ & 10 & $41.7 \%$ & 21 & $51.2 \%$ & & \\
\hline Atypical vessels & 5 & $29.4 \%$ & 8 & $33.3 \%$ & 13 & $31.7 \%$ & & \\
\hline Island & 2 & $11.8 \%$ & 1 & $4.2 \%$ & 3 & $7.3 \%$ & & \\
\hline Peppering & 0 & $0 \%$ & 3 & $12.5 \%$ & 3 & $7.3 \%$ & & \\
\hline White like-scar area & 2 & $11.8 \%$ & 2 & $8.3 \%$ & 4 & $9.8 \%$ & & \\
\hline
\end{tabular}

*with statistical significance 


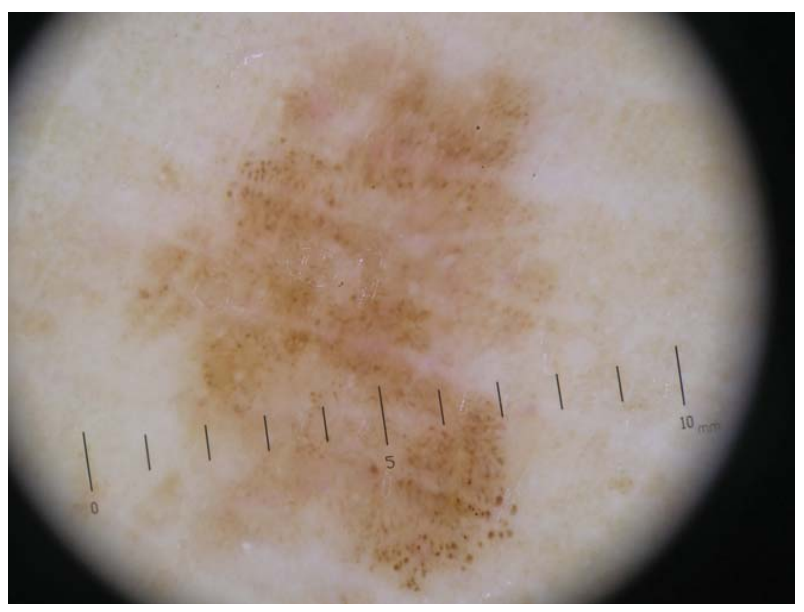

FIGURE 1: Lentigo maligna melanoma in situ on the foot. Dermoscopy shows asymmetry in two axes, two colors, atypical dots and globules and structureless area

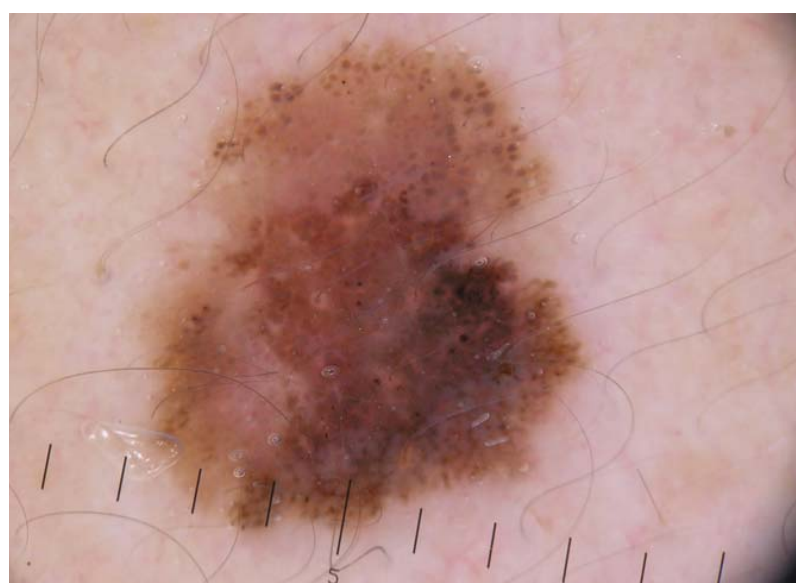

FIGURE 2: Superficial spreading melanoma with a Breslow index of 0.5 $\mathrm{mm}$ in the cervical region. Dermoscopy shows asymmetry in two axes, four colors, atypical globules, streaks, and milky red area

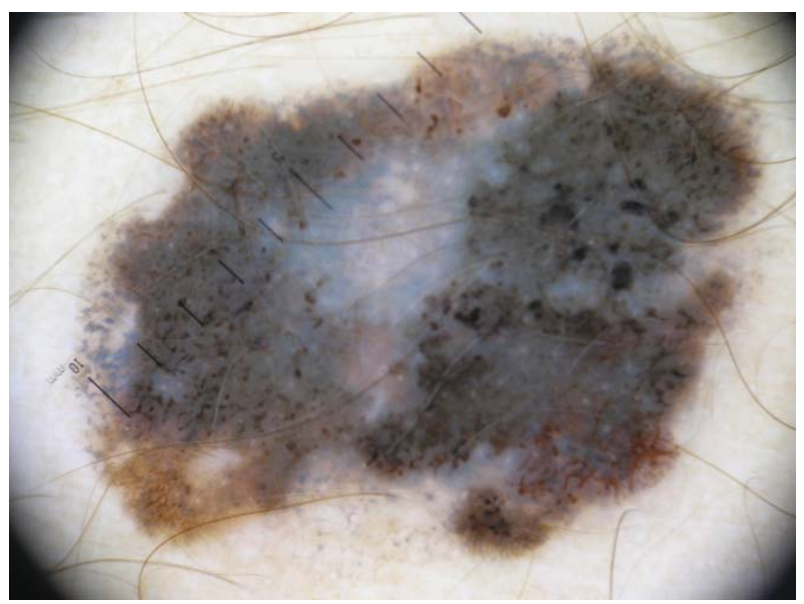

FIGURE 3: Superficial spreading melanoma with a Breslow index of 0.9 $\mathrm{mm}$ on the forearm. Dermoscopy shows asymmetry in two axes, 4 colors, atypical network, streaks, atypical dots and globules, bluewhite veil, and multiple blue-gray dots
Breslow index and dermoscopic criteria, verifying that the presence of atypical network is more associated with early melanomas, being found in $88 \%$ of melanomas in situ. ${ }^{23}$ In our study, this criterion is well observed when all thin melanomas are considered, but it is interesting to note that it is less frequent in melanomas in situ when compared to invasive melanomas less than or equal to $1 \mathrm{~mm}$ thick. Perhaps this tendency could be confirmed by studying a larger sample, observing statistical significance.

Another interesting finding is the difference in the number of colors found in both groups. It is known that all melanomas show 3 or more colors in $85 \%$ of cases and five or more colors in $40 \%$ of cases. ${ }^{24}$ In our study we observed that the higher the number of colors, the greater the possibility that the lesion is invasive, with a 16-fold increased risk if 3 or more colors are found.

Although dermoscopic islands have been described as a characteristic associated with thin melanomas arising from a nevus, in our study the presence of dermoscopic islands in thin melanomas was less frequent. It is important to note that only approximately $25 \%$ of melanomas arise from a pre-existing nevus. ${ }^{13,26}$

Several authors have shown that atypical vessels are rarely found in thin melanomas. ${ }^{18,19,21,25}$ We have found atypical vessels in $31.7 \%$ of thin melanomas. We believe that it is more difficult to assess this criterion retrospectively, considering that most studies use contact dermoscopy to examine the lesions, and contact can compress the vessels and lead to an impaired record during this process.

Our study also shows that invasive melanomas present with a blue-white veil and milky red area more often than melanomas in situ, showing statistical significance. The blue-white veil is a structure that shows tumor nests in the dermis associated with orthokeratosis, acanthosis and hypergranulosis, and is more commonly associated with thick melanomas. ${ }^{15}$ The milky red area appears due to the increased vascularity of the tumor and, although rarely seen, it is the vascular structure with the highest predictive value for the diagnosis of melanoma $(77.8 \%) .{ }^{14}$

Regression structures, like peppering and white scar-like areas, are less observed in thin melanomas, which is in agreement with our findings (less than $10 \%$ of thin melanomas showed regression structures). ${ }^{18,19,23}$ Seidenari et al. evaluated regression structures (blue areas and/or peppering and/or veil and/or white scar-like areas) in 255 melanocytic lesions; they observed these characteristics in benign lesions and also in melanomas in situ and invasive melanomas. ${ }^{27}$ However, this study showed that regression is not only more frequent and extensive in invasive melanomas than it is in in situ lesions, but it also 
has a different morphological expression. While in invasive lesions areas without blue-gray structures usually related to veil and white scar-like area - are frequently observed, in melanoma in situ the disappearance of the network or of dermoscopic structures in circumscribed regions of the lesion gives rise to areas of light brown pigmentation without structures.

Important considerations about the results of this study have to be made. It is relvant to stress that, although significant, some results showed a great confidence interval, which is mainly related to the sample size. Furthermore, this study did not include lesions with a Breslow index greater than $1 \mathrm{~mm}$. Studies that include thicker melanomas would be useful to assess the specificity of the characteristics of thin melanomas and corroborate these findings. Prospective studies, evaluated by different groups of observers, are needed to confirm the

\section{REFERENCES}

1. Brasil. Ministério da Saúde. Instituto Nacional de Câncer José Alencar Gomes da Silva (INCA). Estimativa 2012: incidência de câncer no Brasil. Rio de Janeiro: INCA; 2011. p. 49-50. [acesso 24 Jun 2011]. Disponível em: http://www.inca.gov.br/estimativa/2012/index.asp?ID =1

2. Bafounta ML, Beauchet A, Aegerter P, Saiag P. Is dermoscopy (epiluminescence microscopy) useful for the diagnosis of melanoma? Results of a meta-analysis using techniques adapted to the evaluation of diagnostic tests. Arch Dermatol. 2001;137:1343-50.

3. Mayer J. Systematic review of the diagnostic accuracy of dermatoscopy in detecting malignant melanoma. Med J Aust. 1997;167:206-10.

4. Argenziano G, Cerroni L, Zalaudek I, Staibano S, Hofmann-Wellenhof R, Arpaia N, et al. Accuracy in melanoma detection: A 10-year multicenter survey. J Am Acad Dermatol. 2012;67:54-9.

5. Breslow A. Thickness, cross-sectional areas and depth of invasion in the prognosis of cutaneous melanoma. Ann Surg. 1970;172:902-8.

6. Elder DE. Thin melanoma. Arch Pathol Lab Med. 2011;135:342-6.

7. 7. Balch CM, Gershenwald JE, Soong SJ, Thompson JF, Atkins MB, Byrd DR, et al. Final version of 2009 AJCC melanoma staging and classification. J Clin Oncol. 2009;27:6199-206.

8. NIH Consensus conference. Diagnosis and treatment of early melanoma. JAMA 1992;268:1314-9.

9. GBM.org [Internet]. Conduta terapêutica no Melanoma. [acesso 24 Jun 2011] Disponível em: http://www.gbm.org.br/GBM/socios.aspx

10. Boland GM, Gershenwald JE. Sentinel lymph node biopsy in melanoma. Cancer J. 2012;18:185-91.

11. Gannon CJ, Rousseau DL Jr, Ross MI, Johnson MM, Lee JE, Mansfield PF, et al. Accuracy of lymphatic mapping and sentinel lymph node biopsy after previous wide local excision in patients with primary melanoma. Cancer. 2006;107:2647-52.

12. Argenziano G, Soyer HP, Chimenti S, Talamini R, Corona R, Sera F, et al. Dermoscopy of pigmented skin lesions: results of a consensus meeting via the Internet. J Am Acad Dermatol. 2003;48:679-93

13. Borsari S, Longo C, Ferrari C, Benati E, Bassoli S, Schianchi S, et al. Dermoscopic island: a new descriptor for thin melanoma. Arch Dermatol. 2010;146:1257-62.

14. Argenziano G, Zalaudek I, Corona R, Sera F, Cicale L, Petrillo G, et al. Vascular structures in skin tumors: a dermoscopy study. Arch Dermatol. 2004;140:1485-9.

15. Soyer HP, Argenziano G, Chimenti S, Ruocco V. Dermoscopy of pigmented skin lesions. Eur J Dermatol. 2001;11:270-6.

16. Stolz W, Semmelmayer U, Johow K, Burgdorf WHC. Principles of dermatoscopy of pigmented skin lesions. Semin Cutan Med Surg. 2003;22:9-20.

17. Guitera P, Li LX, Crotty K, Fitzgerald P, Mellenbergh R, Pellacani G, et al. Melanoma histological Breslow thickness predicted by 75-MHz ultrasonography. Br J Dermatol. 2008;159:364-9 reproducibility and validity of these diagnostic criteria.

\section{CONCLUSION}

This study showed that some dermoscopic features may be associated with Breslow index. In general, thin melanomas mainly present asymmetry in two axes, 3 or more colors, atypical dots or atypical globules and atypical network or streaks. Melanomas in situ tend to have up to 2 colors, no blue-white veil and no milky red area. Invasive melanomas tend to exhibit 3 or more colors, a milky red area, blue-white veil, atypical network or streaks. Dermoscopic evaluation plays an important role in diagnostic accuracy, but it can also be used to estimate preoperative thickness. Other prospective, multicentered studies of a larger sample and that include thick melanomas are needed to confirm these findings.
18. Argenziano G, Fabbrocini G, Carli P, De Giorgi V, Delfino M. Epiluminescence microscopy: criteria of cutaneous melanoma progression. J Am Acad Dermatol. 1997;37:68-74.

19. Lorentzen HF, Weismann K, Larsen FG. Dermatoscopic prediction of melanoma thickness using latent trait analysis and likelihood ratios. Acta Derm Venereol. 2001;81:38-41.

20. Hayashi K, Koga H, Uhara H, Saida T. High-frequency 30-MHz sonography in preoperative assessment of tumor thickness of primary melanoma: usefulness in determination of surgical margin and indication for sentinel lymph node biopsy. Int J Clin Oncol. 2009;14:426-30.

21. Argenziano G, Fabbrocini G, Carli P, De Giorgi V, Delfino M. Clinical and dermatoscopic criteria for the preoperative evaluation of cutaneous melanoma thickness. J Am Acad Dermatol. 1999;40:61-8.

22. Carli P, de Giorgi V, Palli D, Giannotti V, Giannotti B. Preoperative assessment of melanoma thickness by $A B C D$ score of dermatoscopy. J Am Acad Dermatol. 2000;43:459-66.

23. Stante M, De Giorgi V, Cappugi P, Giannotti B, Carli P. Non-invasive analysis of melanoma thickness by means of dermoscopy: a retrospective study. Melanoma Res. 2001:11:147-52.

24. Stolz W, Braun-Falco O, Bilek P, Landthaler M, Burgdorf W, Cognetta A. Atlas Colorido de Dermatoscopia. 2 ed. Rio de Janeiro: DiLivros; 2002.

25. Gkalpakiotis S, Arenbergerova M, Arenberger P, Sefrnova P. Dermoscopic features of thin melanomas. J Am Acad Dermatol. 2012:66:AB83.

26. Stolz W, Schmoeckel C, Landthaler M, Braun-Falco 0 . Association of early malignant melanoma with nevocytic nevi. Cancer. 1989;63:550-5.

27. Seidenari S, Ferrari C, Borsari S, Benati E, Ponti G, Bassoli S, et al. Reticular greyblue areas of regression as a dermoscopic marker of melanoma in situ. $\mathrm{Br} \mathrm{J}$ Dermatol. 2010;163:302-9.
MAILING ADDRESS:
Vanessa Priscilla Martins da Silva
Hospital Universitário - Serviço de Dermatologia
Rua Maria Flora Pausenwang, s/n. - Campus Universitário
Trindade 88040-900 - Florianópolis - SC
Brazil
E-mail:med.nessa@gmail.com

How to cite this article: Silva VPM, Ikino JK, Sens MM, Nunes DH, Di Giunta G. Dermoscopic features of thin melanomas: a comparative study of melanoma in situ and invasive melanomas smaller than or equal to $1 \mathrm{~mm}$. An Bras Dermatol. 2013;88(5):712-7. 